\title{
PobReZA Y ESPACIOS ABANDONADOS: ANÁlisis ENFOCADO EN TRES CIUDADES FRONTERIZAS DEL NORTE DE MÉXICO
}

\section{Poverty and Abandoned Spaces: An Analysis Focused on Three Border Cities in Northern Mexico}

\author{
Claudio Curzio* \\ doi: https://doi.org/10.31644/ED.V8.N2.2021.A06
}

\begin{abstract}
Resumen: Los espacios abandonados pueden comprenderse como un fenómeno urbano relacionado con aquellas edificaciones obsoletas que han ido perdiendo gradualmente su condición de habitabilidad. De esta manera, el objetivo del presente artículo es analizar cuál es la naturaleza de su distribución geo-espacial, haciendo énfasis en exponer y examinar la correlación que existe entre este fenómeno y la desigualdad socio-económica de la población. Para ello, se presenta un análisis geo-espacial enfocado en tres ciudades fronterizas del norte de México - Mexicali, Nuevo Laredo y San Luis Río Colorado- Se implementó una metodología descriptivo-comparativa basada en efectuar levantamientos digitales y físicos de los espacios abandonados, con lo cual se conformaron bases de datos para cada una de las ciudades. De este modo, usando técnicas de estadística y análisis espacial fue posible obtener los modelos y resultados. Como conclusión, se presenta una discusión comparativa entre las tres ciudades, mostrando las diferencias y coincidencias detectadas.
\end{abstract}

Palabras clave: espacios obsoletos abandonados en Mexicali, Nuevo Laredo y San Luis Río Colorado, espacios residuales, análisis geo-espacial, pobreza urbana.

\begin{abstract}
Abandoned spaces can be understood as an urban phenomenon related to those obsolete buildings that have gradually lost their condition of habitability. Thereafter, the objective of this article is to analyze the nature of its geo-spatial distribution, emphasizing the correlation between this phenomenon and the socio-economic inequality of the population. To this end it offers a geospatial analysis focused on three border cities in the north of Mexico - Mexicali, Nuevo Laredo and San Luis Río Colorado-. A descriptive-comparative methodology was carried out based on digital and physical surveys of the abandoned spaces, with which databases were created

\footnotetext{
* Dr. en Ciencias de los Ámbitos Antrópicos, investigador independiente, especialista en temas de geografía urbana y análisis geo-espacial. ORCiD: https://orcid.org/0000-0001-8696-617X. Correo-e: claudio7curzio@icloud.com.

Fecha de recepción: 25/09/2020. Fecha de aceptación: 29/04/2021. Fecha de publicación: 30/07/2021.

(cc) BY-NC-ND
}

EntreDiversidades. Revista de Ciencias Sociales y Humanidades, Vol. 8, Núm. 2 (17), julio-diciembre 2021. Páginas: 119-144 ISSN-e: 2007-7610. https://doi.org/10.31644/ED.V8.N2.2021.A06 
for each of the cities. Thus, using statistical and spatial analysis techniques it was possible to obtain the models and results. The article closes with a comparative discussion between the three cities, as well as with the differences and coincidences detected.

Keywords: obsolete abandoned spaces in Mexicali, Nuevo Laredo and San Luis Río Colorado, residual spaces, socio-spatial segregation, urban poverty.

\section{Introducción}

Hablar sobre espacios abandonados nos lleva a reflexionar acerca de todos aquellos elementos urbanos que han ido quedando olvidados, relegados, perdidos, y en donde claramente es posible observar un proceso de degradación que puede inclusive llegar al punto de reducir gradualmente el elemento urbano a una mínima expresión, manifestándose en términos del paisaje mediante la presencia de ruinas que llegan a permanecer indefinidamente en el sitio. Básicamente hablamos, por ejemplo, de cimentaciones expuestas, fragmentos de muros, techumbres derrumbadas, incluso simplemente puede tratarse de una serie de escombros de distinta índole, pero en general todos estos vestigios son una invitación para de cierta manera echar a volar la imaginación del observador en cuanto a reflexionar sobre cuál habrá sido el uso y vocación de dichos espacios (ver Figura 1).

Figura 1. Espacio abandonado en la ciudad de San Luis Río Colorado, Sonora

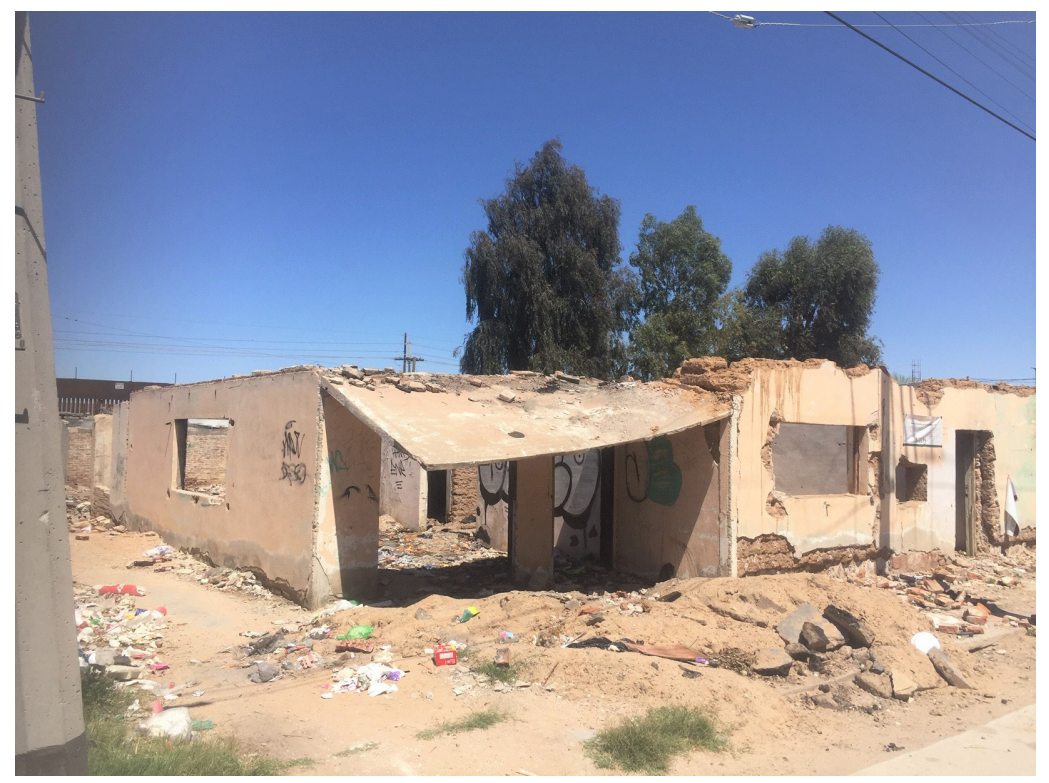

Como puede observarse (Caso B-IN-SL-052), se trata de una serie de ruinas que parecieran denotar lo que en su momento fue probablemente una vivienda, la cual se encuentra localizada a 60m del muro fronterizo, sobre la calle denominada Capital Carlos G. Calles.

Fuente: Elaboración propia.

EntreDiversidades. Revista de Ciencias Sociales y Humanidades, Vol. 8, Núm. 2 (17), julio-diciembre 2021. Páginas: 119-144 ISSN-e: 2007-7610. https://doi.org/10.31644/ED.V8.N2.2021.A06 
Por lo general, este tipo de espacios abandonados constituyen un tema que pasa desapercibido, no solo para los habitantes sino también a nivel académico, e incluso ajeno a la atención y cuidado de instancias gubernamentales, ya que frecuentemente esta problemática no es abordada dentro de los planes de desarrollo urbano municipales. Vale la pena señalar que brindarles atención va más allá de ser una cuestión paisajística, debido a que son áreas que, a pesar de haber perdido su función original, y además de su importancia arquitectónica, mantienen valores y contenidos con identidad (Melelli, 2012: 13). Existen ocasiones en las que algunos de estos elementos urbanos pueden quedar olvidados en términos utilitarios, sin embargo, quizá no se han borrado de la memoria de los habitantes debido a que representan vivencias y recuerdos que se mantienen presentes, pese a que únicamente queden en pie algunos vestigios de lo que algún día fue ese espacio.

Actualmente, hay muchas interrogantes respecto al tema de los espacios abandonados. Por ejemplo, en el ámbito teórico poco se ha reflexionado sobre cuáles son sus principales tipologías y los motivos fundamentales que llevan a que un espacio caiga en el abandono. Al mismo tiempo, también se desconoce la magnitud de esta problemática urbana en términos cuantitativos, es decir, ¿cuál es el índice de densidad?, ¿qué superficie individual tienen?, ¿cuánta superficie total representan?, ¿la totalidad de casos tiene alguna relación con la escala de la ciudad? Por otra parte, tampoco se tiene conocimiento sobre la naturaleza de cómo se distribuyen e interconectan con las ciudades: ¿presentan patrones de aglomeración definidos?, o bien ¿simplemente se agrupan de forma aleatoria en el espacio urbano?

De esta manera, el presente artículo tiene como objetivo brindar una serie de respuestas ante las interrogantes previamente mencionadas, al mismo tiempo que se plantea también un análisis de correlación para determinar si los rangos de pobreza de la población pueden constituirse como un factor vinculante (cuantitativa y espacialmente) con el número de espacios abandonados en las ciudades. Para ello, se expone el análisis de diversos autores con el fin de definirlos, caracterizarlos y compararlos; lo anterior, busca constituir una base teórica con respecto al significado y características de los espacios abandonados. Posteriormente, se describe la metodología empleada, la cual consistió en identificar y registrar cada uno de estos espacios en las áreas de estudio seleccionadas, conformadas por la conjunción de distintas $\mathrm{AGEB}^{1}$ en los núcleos urbanos de las ciudades fronterizas de Mexicali, Nuevo Laredo y San Luis Río Colorado.

Una vez identificados los espacios abandonados en cada una de las ciudades y registrados en una base de datos, se procedió a elaborar diversos modelos espaciales que plasmaran gráficamente la localización de cada uno de los casos de estudio. A continuación, los resultados fueron analizados de forma correlacional con el estudio de medición de pobreza realizado en el año 2015 por el Consejo Nacional de Evaluación de la Política de Desarrollo Social (CONEVAL, 2018).

De esta forma, los resultados derivados de la correlación entre ambas variables (número y localización de espacios abandonados contrastados por el rango de pobreza) fueron contrastados mediante dos tipos de análisis geo-espacial. Por una parte, se determinó el comportamiento

${ }^{1}$ El término AGEB (áreas geo-estadísticas básicas) es un concepto empleado por INEGI, cuyo significado es: un área geográfica ocupada por un conjunto de manzanas perfectamente delimitadas por calles, avenidas, andadores o cualquier otro rasgo de fácil identificación.

EntreDiversidades. Revista de Ciencias Sociales y Humanidades, Vol. 8, Núm. 2 (17), julio-diciembre 2021. Páginas: 119-144 ISSN-e: 2007-7610. https://doi.org/10.31644/ED.V8.N2.2021.A06 
particular del objeto de estudio en el interior de las ciudades seleccionadas (análisis intra-urbano) $y$, en segundo término, se generó un debate orientado a comparar las coincidencias y diferencias de los patrones espaciales detectados entre cada una de las tres ciudades objeto de la presente investigación (análisis interurbano).

\section{Una aproximación al contexto socio-económico de las ciudades fronterizas}

Hablar sobre las ciudades fronterizas del norte de México significa referirse principalmente a un conjunto integrado por diversas urbes, entre las que destacan, principalmente, Tijuana, Ciudad Juárez, Mexicali, Matamoros, Reynosa, Nuevo Laredo, Nogales, San Luis Río Colorado y Piedras Negras. En términos demográficos, se estima que actualmente viven más de 7 millones de personas en dicha región (ver Tabla 1). En palabras de Díaz-Bautista (2003: 1091), "la frontera norte de México es una mezcla de realidades económicas, sociales y culturales integradas por un conjunto de regiones a lo largo de más de 3,200 kilómetros de línea fronteriza con Estados Unidos”.

Así, la decisión de analizar dicho sector geográfico se tomó debido a que su misma naturaleza fronteriza trae consigo una serie de particularidades que no suelen presentarse en otro tipo de ciudades mexicanas, como por ejemplo, podría destacarse la movilidad de su población y también el dinamismo de sus actividades comerciales; en palabras de Garduño (2016: 134), "las entidades, ciudades o comunidades fronterizas son sitios por excelencia de disputa y desplazamiento, característicos de la globalización y la sobremodernidad”. Coincidentemente, Ceniceros y Ettinger (2020: 182) señalan que "esta serie de territorios compartidos, se caracteriza por la presencia de un intercambio constante de personas, mercancías e ideas". Este conjunto de características han llevado a que el septentrión mexicano sea una fuente de investigación muy singular para economistas, urbanistas, sociólogos, geógrafos e incluso historiadores.

En consecuencia, se puede afirmar que la migración y movilidad transfronteriza modifica las relaciones socio-espaciales y, por tanto, también transforma el paisaje urbano. Así, después de recorrer las estructuras urbanas de las principales ciudades fronterizas es posible observar una serie de diversos lugares inutilizados — vacíos urbanos, espacios abandonados y remanentes urbanos - Por tanto, el paisaje de este tipo de ciudades revela que algo distinto y muy singular está ocurriendo en ellas, "al estudiar la región fronteriza desde una mirada espacial arquitectónica, se advierte un vacío" (Ceniceros y Ettinger, 2020: 182).

En términos sociales el concepto de frontera implica no solo la idea de separación, pues define los límites propios de individuos y sociedades, sino por necesidad su opuesto, es decir, la idea de relación, en tanto que vincula personas y sociedades con estructuras históricas y mentales particulares (Lara, 2011: 9). Un ejemplo de esta asociación radica en la movilidad de la fuerza laboral que se desplaza diariamente entre ambos lados de la frontera, donde es común observar personas que duermen en territorio mexicano, pero durante el día se trasladan para trabajar en distintas ciudades norteamericanas. Concretamente, esto ocurre claramente en Tijuana y San Diego (California), Ciudad Juárez y El Paso (Texas), Nuevo Laredo y Laredo (Texas), denominadas "espejo" o "gemelas", las cuales Tambi (2016: 7) concibe como aquellas ciudades fronterizas que "resultan adyacentes entre sí, es decir, en donde sus condiciones de vecindad están

EntreDiversidades. Revista de Ciencias Sociales y Humanidades, Vol. 8, Núm. 2 (17), julio-diciembre 2021. Páginas: 119-144 ISSN-e: 2007-7610. https://doi.org/10.31644/ED.V8.N2.2021.A06 
expuestas a la integración, lo cual se manifiesta con relaciones bilaterales estables y de cooperación mutua”. También existe otro tipo de nexo socio-económico en aquellos enclaves fronterizos que no cuentan con un vecino inmediato con el cual puedan emular la dinámica bilateral de las ciudades espejo. Por ejemplo, el caso de Mexicali, donde probablemente no se manifiesta un vínculo tan claro con sus vecinas más próximas - Calexico o El Centro, ambas en California-, sino más bien con San Diego y Los Ángeles, que se sitúan como el mayor polo de atracción en términos laborales. Paralelamente, en el caso de San Luis Río Colorado este fenómeno se da principalmente con la ciudad de Yuma (Arizona).

Respecto al tema del ámbito económico, es importante recalcar que "en términos nacionales, el PIB de la región de la frontera norte de México representa más de $20 \%$ del total nacional, porcentaje que pone en evidencia su gran importancia económica” (Díaz-Bautista, 2003: 1094). En esta realidad, es necesario hacer un énfasis en señalar el papel que ha jugado la implementación del Tratado de Libre Comercio para América del Norte (TLCAN), ${ }^{2}$ un parteaguas que impulsó una transformación (de distintas magnitudes) en las economías locales de las ciudades fronterizas; "este tratado marcó una etapa importante de consolidación de la integración de la economía mexicana en el mercado norteamericano y de su inserción en el proceso de globalización, creando ventajas comparativas en finanzas, comercio, tecnología y manufactura" (Coubés, 2003: 8). De esta manera, la vocación económica de la región ha venido transformándose de forma más significativa en las últimas tres décadas.

Aunado al empleo local manufacturero, las remesas económicas también representan otro gran pilar de las economías fronterizas. Concretamente, el análisis realizado por Castillo y González (2020: 24) describe a detalle esta situación con respecto específicamente a la región septentrional del país, ${ }^{3}$ en donde existió un sustantivo crecimiento del total nacional de recepción de remesas, que pasó de 390 millones de dólares en el año 1995 a 2,819 millones para el año 2007, lo cual significa que el monto monetario recibido en 1995 fue multiplicado por siete veces para el 2007 (con un crecimiento anual promedio del 51,9\%).

Sin embargo, también cabe aclarar que los beneficios del TLCAN no se han presentado de forma homogénea para todas las urbes fronterizas. En ese sentido, Coubés (2003: 25) señala que "las grandes ciudades como Tijuana y Ciudad Juárez están del lado de las beneficiadas, en tanto que las localidades medias como Nuevo Laredo y Matamoros aparecen, en términos de empleo, como las perdedoras de la implementación de dicho tratado". Esta asimetría entre ciudades no solo se ve reflejada en términos económicos, sino también en los distintos rangos de pobreza de las mismas (ver Tabla 1).

\footnotetext{
${ }^{2}$ El TLCAN entró en vigor el $1^{\circ}$ de enero de 1994 con el objetivo de fomentar el comercio entre México, Estados Unidos y Canadá.

${ }^{3}$ En dicho estudio, la región septentrional abarca los estados de Baja California Sur, Baja California Norte, Sonora, Chihuahua, Coahuila, Nuevo León, Tamaulipas y Sinaloa.
}

EntreDiversidades. Revista de Ciencias Sociales y Humanidades, Vol. 8, Núm. 2 (17), julio-diciembre 2021. Páginas: 119-144 ISSN-e: 2007-7610. https://doi.org/10.31644/ED.V8.N2.2021.A06 
Tabla 1. Información estadística demográfica y de rangos de pobreza

\begin{tabular}{|lcc|}
\multicolumn{1}{|c|}{ Ciudad Fronteriza } & Población & Rango de pobreza (\%) 2015 \\
\hline Ciudades de gran escala. & $(2020)$ & \\
Más de 1 millón de habitantes: & & \\
1- Tijuana, BC. & & $29.50 \%$ \\
2- Ciudad Juárez, CHI & $1,922,523$ & $26.40 \%$ \\
3- Mexicali, BC. & $1,512,450$ & $25.70 \%$ \\
Ciudades de escala intermedia. & $1,049,792$ & \\
400,000 - 1 millón de habitantes & & $34.80 \%$ \\
4- Reynosa, TAM & & $39.70 \%$ \\
5- Matamoros, TAM & & $35.50 \%$ \\
6- Nuevo Laredo, TAM. & 704,767 & \\
Ciudades de menor escala. & 541,979 & \\
Menores a 400,000 habitantes & 425,058 & \\
7- Nogales, SON. & & $28.40 \%$ \\
8- San Luis Río Colorado, SON. & & \\
9- Piedras Negras, COAH. & & \\
\hline
\end{tabular}

Fuente: Elaboración propia con base en información de INEGI (2021) y CONEVAL (2018).

Las cifras anteriores señalan que las ciudades con los índices de pobreza más bajos son Nogales, Mexicali y Ciudad Juárez, con rangos de pobreza equivalentes a 23.9\%, 25.7\% y 26.4\%, respectivamente, mientras que las más rezagadas fueron San Luis Río Colorado, Matamoros y Nuevo Laredo, con un rango de pobreza de 40.3\%, 39.7\% y 35.5\%, respectivamente (CONEVAL, 2018). Estos datos coinciden con las afirmaciones realizadas por Pick, Viswanathan y Hettrick (2001), Anderson y Gerber (2007) y Garza-Rodríguez (2016) en torno a que la pobreza en ambos lados de la frontera es mucho mayor en el este que en el oeste (la única notable excepción se presenta en San Luis Río Colorado). Así, es Tamaulipas el estado fronterizo con mayor rango de pobreza, mientras que Baja California supone el que menor rezago presenta.

En síntesis, la región fronteriza del norte de México cuenta con una privilegiada posición geográfica que puede expresarse en términos de desarrollo económico, sin embargo, este no se ha presentado propiamente de manera homogénea. Como explica Díaz-Bautista (2003: 1091), la pobreza junto con el centralismo y el desempleo se posicionan como los principales problemas estructurales de las ciudades fronterizas, los cuales "muchas veces se tratan al margen de las grandes políticas de desarrollo y se desvinculan de su entorno territorial".

EntreDiversidades. Revista de Ciencias Sociales y Humanidades, Vol. 8, Núm. 2 (17), julio-diciembre 2021. Páginas: 119-144 ISSN-e: 2007-7610. https://doi.org/10.31644/ED.V8.N2.2021.A06 


\section{Definición y características de los espacios abandonados}

El tema de los espacios abandonados contiene una particular complejidad debido a que es un fenómeno que se presenta con distintas tipologías y escalas. Puede tratarse simplemente de una edificación aislada que fue abandonada y paulatinamente el tiempo se encargó de ir degradando sus componentes físicos, o bien por ejemplo también podemos encontrar grupos específicos de edificaciones localizadas en ciertas áreas geográficas muy particulares de una ciudad. Finalmente, en casos extremos, la escala del objeto de estudio también puede incluso llegar a abarcar ciudades enteras, es decir, localidades que fueron abandonadas por completo. ${ }^{4}$

Los espacios catalogados desde la óptica urbanística como abandonados son una manifestación del anti-espacio urbano (Trancik, 1986) y comúnmente también han sido diversos los autores que han abordado este tema desde el ámbito de los espacios residuales (Clément, 2007; Curzio, 2008 y Díaz Cruz, 2016). En este sentido, desde el punto de vista etimológico, el origen de la palabra "residuo" se deriva de la raíz latina residûum, cuya acepción es: "1. Parte o porción que queda de un todo 2. Lo que resulta de la descomposición o destrucción de una cosa. 3. Alg. y Arit. Resultado de la operación de restar" (RAE, 2019). Tomando como base dicho significado, es posible reconocer la existencia de una sub-categoría fundamentada en los diversos orígenes que pueden llegar a presentar los espacios residuales; concretamente, retomando reflexiones teóricas propuestas previamente por Curzio (2008), se plantea que el término "residual" da pie a la constitución de dos objetos de estudio distintos. Por una parte, destacan los remanentes urbanos, los cuales son básicamente aquellos espacios que surgen de un proyecto de mayor escala, es decir, son resultantes de un sobrante — por ejemplo, derechos de vía o áreas bajo puentes, los cuales no pueden considerarse como abandonados debido a que no tuvieron algún tipo de uso preexistente-. A su vez, también derivado del concepto "residual", se encuentran los espacios abandonados, que podrían definirse brevemente como aquella resultante obtenida de la descomposición o destrucción de un espacio urbano previamente existente y que ahora ya no cumple una función definida debido a que ha perdido su condición de habitabilidad. ${ }^{5}$ Coincidentemente, Cléments (2007: 6) señala que los espacios residuales son el resultado del abandono de una actividad. A su vez, dicho autor también hace referencia a la pérdida de identidad y función que caracteriza a este tipo de espacios a los que además califica como desprovistos de función. Sin embargo, la visión de Cléments pareciera incompleta, en cuanto a que no logra discernir una diferencia tipológica en su definición, es decir, no establece distinciones entre los espacios abandonados y los vacíos urbanos en la caracterización de los espacios residuales. Por otra parte, tampoco aborda el tema desde una visión geo-espacial, lo cual implica que no genera aportaciones sobre la distribución que tienen este tipo de espacios dentro de las ciudades.

En primer término, cuando se empieza a reflexionar sobre el objeto de estudio, una de las principales interrogantes se da en torno a cuáles son los orígenes que pueden tener los espacios abandonados. En ese sentido, destacan principalmente dos grandes categorías. Por una parte, se

\footnotetext{
${ }^{4}$ Dentro de algunos ejemplos a nivel mundial es posible señalar las ciudades de Varosha en Chipre, Pripyat en Ucrania y Hashima en Japón.

${ }^{5}$ Se interpreta que la habitabilidad es el conjunto de ciertas condiciones (físicas y no físicas) que buscan satisfacer las necesidades y aspiraciones de los habitantes, lo cual en consecuencia es lo que permite a un ser vivo habitar un lugar.
}

EntreDiversidades. Revista de Ciencias Sociales y Humanidades, Vol. 8, Núm. 2 (17), julio-diciembre 2021. Páginas: 119-144 ISSN-e: 2007-7610. https://doi.org/10.31644/ED.V8.N2.2021.A06 
encuentran aquellos que resultan de un proceso de degradación (obsolescencia), es decir, espacios que dejan de responder a las necesidades para las que fueron proyectados, lo que conlleva el inicio de una metamorfosis, una transformación de lo que antes era un elemento urbano activo (funcional) en uno de tipo abandonado, en este caso, en un residuo urbano (obsoleto). Por otra parte, existe un segundo tipo que está relacionado con aquellas construcciones que resultaron inconclusas, es decir, nunca se terminaron de construir y así permanecieron dentro del paisaje de la ciudad. En el caso particular de la vivienda, se trata de obras que jamás fueron habitadas, y en el caso de cualquier otra tipología urbana — como comercios, industrias, hospitales, estaciones de transporte, etc.—, se consideran construcciones que en ningún caso llegaron a ser aprovechadas por la población, situación por la cual permanecen deshabitadas e inutilizadas.

Una vez que se han expuesto los posibles orígenes que pueden presentar los espacios abandonados, es necesario también recalcar ciertas características físicas que resultan distintivas de los mismos. Así, destaca el hecho de que cuentan con un grado perceptible de deterioro, es decir, ya han perdido su condición de habitabilidad. Esta situación frecuentemente se ve manifestada mediante la presencia de escombros, como por ejemplo, derrumbes estructurales de sus muros y techumbres. Además, es habitual que ya no existan elementos físicos como puertas o ventanas que protejan a dicha edificación, lo cual suele facilitar ciertas muestras de vandalismo, por lo que este tipo de espacios urbanos se suelen identificar como potenciales focos de inseguridad y violencia. En ese sentido, es prudente citar a Shane (2012: 7), quien menciona que un espacio puede ser considerado abandonado siempre y cuando constituya "un peligro para la salud y el bienestar de la comunidad; así como también debe estar vacante por un período de tiempo". Sin duda, la aportación que realiza este autor es interesante, ya que puntualiza sobre las implicaciones sociales que este tipo de lugares pueden llegar a tener para los habitantes y su comunidad. Del mismo modo, también brinda una definición bastante clara y completa sobre el objeto de estudio:

El término edificio abandonado connota una imagen de un edificio que está desocupado y en un estado de grave deterioro, tal vez tapiado, cubierto de basura y garabateado con grafitis. Aunque un edificio puede poseer estos atributos, que evocan miedo y precipitan el declive en una comunidad, es difícil definir legalmente a un edificio abandonado ya que no existe definición. Por lo tanto, es mejor usar una interpretación amplia que incluya una variedad de propiedades y condiciones (Shane, 2012: 6).

Nefs (2006) ha estudiado específicamente el tema de la degradación en los espacios abandonados relacionados con el rubro industrial, para lo cual emplean un término muy específico denominado brownfield, definido como: "una propiedad industrial o comercial que está abandonada o sub-utilizada y con frecuencia está contaminado ambientalmente, especialmente también son considerados como un sitio potencial para la rehabilitación urbana” (2006: 49) (ver Figura 2).

EntreDiversidades. Revista de Ciencias Sociales y Humanidades, Vol. 8, Núm. 2 (17), julio-diciembre 2021. Páginas: 119-144 ISSN-e: 2007-7610. https://doi.org/10.31644/ED.V8.N2.2021.A06 


\section{Figura 2. Edificación de tipo comercial abandonada en Nuevo Laredo}

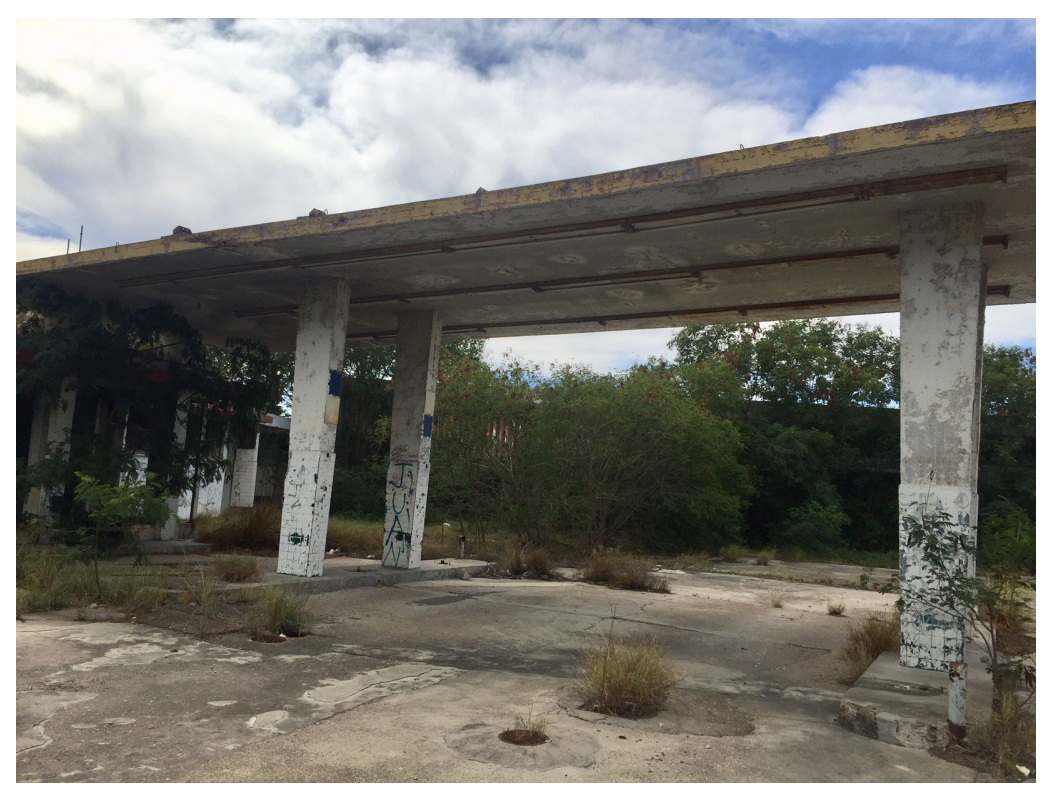

Como se percibe en la fotografía (Caso B-CI-NL-010), se trata de una antigua gasolinera que se localiza sobre la Av. Reforma, a un costado del centro comercial denominado como Plaza Real. Este caso de estudio constituye el tipo de espacios abandonados que suelen ser denominados como brownfield. Fuente: Elaboración propia.

De esta manera, la marginación influye directamente en diversos ámbitos, uno de los cuales se da en términos del paisaje urbano. La calidad de la imagen de la ciudad es producto de un conjunto de representaciones visuales, donde el valor estético juega un papel preponderante. Por ejemplo, esto queda de manifiesto en cuanto a la plusvalía que puede llegar a tener un barrio determinado, en palabras de Muñoz (2005: 82), "hoy en día parece evidente que la imagen se ha convertido en una condición necesaria del proceso mismo de la transformación urbana, lo que explica por qué la imagen urbana necesita promoverse y publicitarse antes de que se coloque un solo ladrillo". Esta situación lleva a reflexionar sobre la posible injerencia que los espacios abandonados puedan llegar a tener en términos de alterar negativamente los valores del mercado inmobiliario. ${ }^{6}$

En síntesis, lograr rehabilitar este tipo de espacios resulta de suma importancia, debido a que más allá de la repercusión hacia el paisaje urbano, su misma condición de abandono frecuentemente conlleva que sean lugares utilizados para llevar a cabo actos delictivos y/o de vandalismo. Del mismo modo, también se presentan como puntos recurrentes para la "acumulación de basura y escombros, creando un evidente problema ambiental al interior de los barrios, lo que se suma a

\footnotetext{
${ }^{6}$ Para mayores detalles sobre cómo se vincula el tema de los espacios abandonados con el paisaje urbano pueden consultarse las aportaciones realizadas por Díaz Cruz (2016), quien propone el concepto del paisaje residual, y la visión de Peimbert (2016), el cual establece un concepto paralelo denominado paisaje intersticial.
}

EntreDiversidades. Revista de Ciencias Sociales y Humanidades, Vol. 8, Núm. 2 (17), julio-diciembre 2021. Páginas: 119-144 ISSN-e: 2007-7610. https://doi.org/10.31644/ED.V8.N2.2021.A06 
la precaria e irregular recolección de los mismos" (Espósito-Galarce y Coutinho, 2016: 19), por tanto, además de ser un problema de tipo ambiental, también sin duda termina por ser factor detonante de la segregación socio-espacial.

\section{Metodología \\ Descripción general}

El diseño metodológico está basado en un estudio de correlación de tipo descriptivo-comparativa de carácter selectivo. Así mismo, cabe señalar que la investigación realizada fue de corte transversal, en cuanto a que se trata de un estudio práctico efectuado en un tiempo específico - concretamente, la recopilación de información fue llevada a cabo entre octubre del ańo 2019 y febrero del 2020 - . De este modo, el objetivo de la metodología fue lograr brindar una respuesta a la hipótesis planteada, concretamente se pretendió determinar si la distribución geográfica y el índice de densidad de los espacios abandonados resulta coincidente con las áreas que presentan los rangos más altos de pobreza.

En la primera sección de la investigación se aplicó el método inductivo para explorar, describir y generalizar perspectivas teóricas referentes al objeto de estudio. Por tanto, con base en un análisis reflexivo de la literatura existente, se trató de recopilar hechos, procesos y estructuras con el fin de alcanzar un conocimiento más profundo y detallado sobre el tema de los espacios abandonados y también sobre el contexto socio-económico de las ciudades fronterizas del norte de México.

Posteriormente, el ámbito cuantitativo estuvo enfocado en adquirir, describir y aplicar conocimientos basados en mediciones objetivas, la demostración de la causalidad y en la generación de resultados. Específicamente, para fines del presente ejercicio práctico fueron seleccionadas tres ciudades, que además de ser fronterizas tuvieran la singularidad de manifestarse con escalas poblacionales distintas (ver Tabla 1), esto con el objetivo de que el análisis geo-espacial y correlacional lograra también incluir una discusión comparativa acerca de cómo se comporta el objeto de estudio en función de las diversas escalas que presentan dichas urbes. Así, en primer lugar se seleccionó la ciudad de Mexicali (Baja California), la cual cuenta con una población estimada de 1087478 habitantes (CONAPO, 2020) y, por tanto, considerada como de gran escala; por otra parte, en segundo término, fue elegida la ciudad de Nuevo Laredo (Tamaulipas), con una población de 421295 habitantes (CONAPO, 2020), clasificada como de escala intermedia; $y$, finalmente, la tercera ciudad escogida fue de una escala menor, la ciudad de San Luis Río Colorado (Sonora), que tiene una población estimada de 226478 habitantes (CONAPO, 2020).

Posteriormente, en cada una de las urbes se ubicaron e integraron un conjunto de AGEB (áreas geo-estadísticas básicas que fueron obtenidas de INEGI, 2018), conformando así un gran polígono que constituyó el área geográfica de estudio en cada una de las ciudades (ver Figuras 3, 4 y 5$)$.

EntreDiversidades. Revista de Ciencias Sociales y Humanidades, Vol. 8, Núm. 2 (17), julio-diciembre 2021. Páginas: 119-144 ISSN-e: 2007-7610. https://doi.org/10.31644/ED.V8.N2.2021.A06 
Figura 3. Fotografía aérea de la integración de 151 AGEB del área geográfica de estudio en Mexicali, Baja California

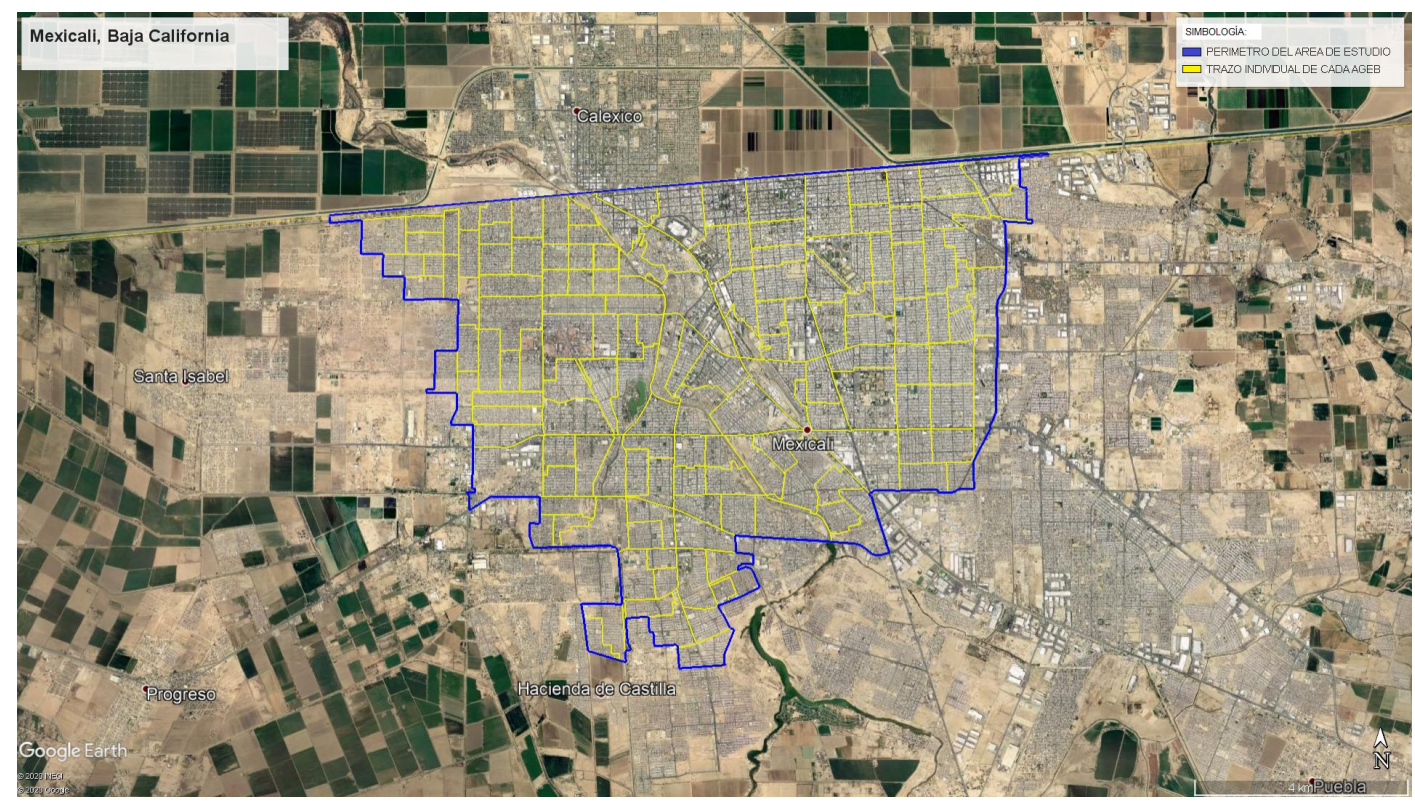

Fuente: Elaboración propia con base en información de INEGI (2018).

Figura 4. Fotografía aérea de la integración de 110 AGEB del área geográfica de estudio en Nuevo Laredo, Tamaulipas

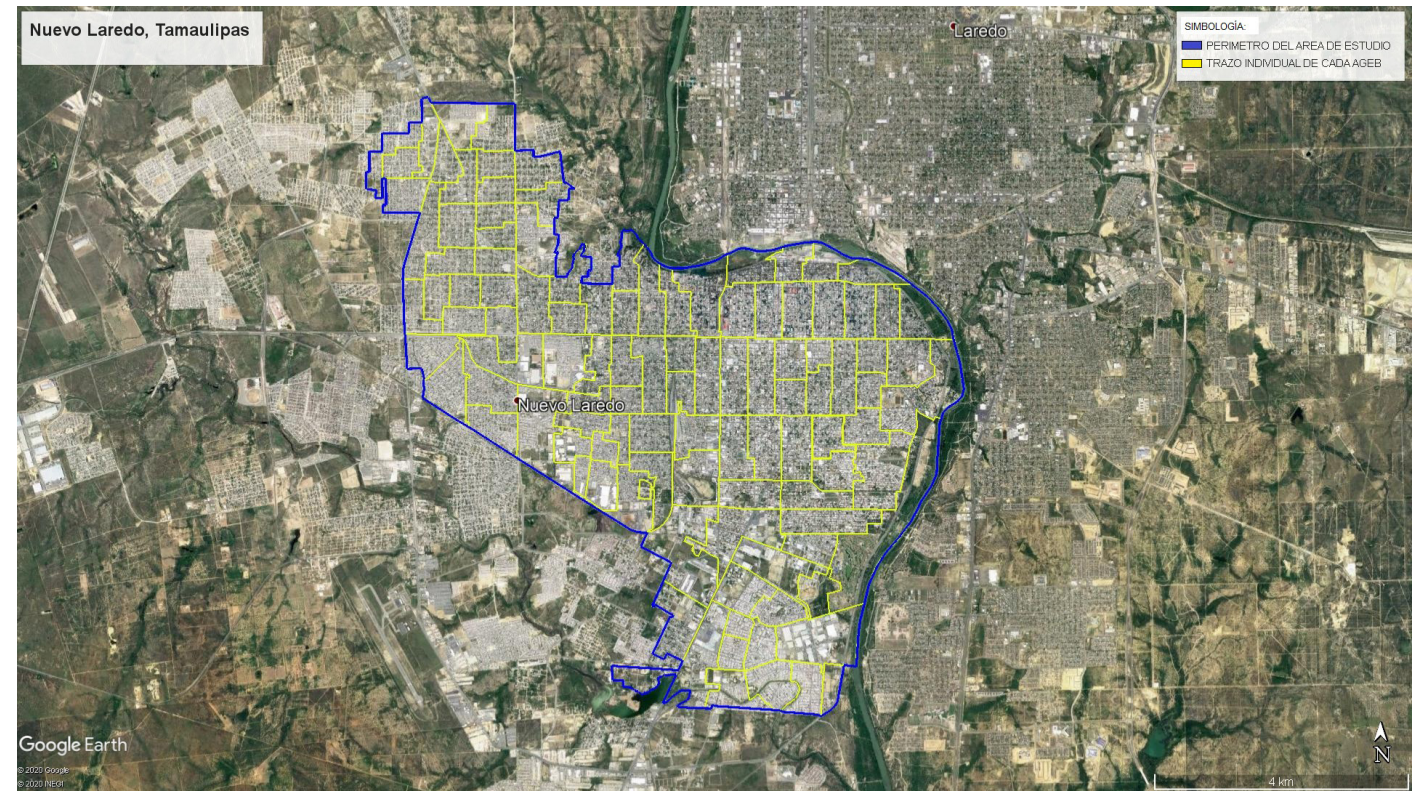

Fuente: Elaboración propia con base en información de INEGI (2018).

EntreDiversidades. Revista de Ciencias Sociales y Humanidades, Vol. 8, Núm. 2 (17), julio-diciembre 2021. Páginas: 119-144 ISSN-e: 2007-7610. https://doi.org/10.31644/ED.V8.N2.2021.A06 
Figura 5. Fotografía aérea de la integración de 97 AGEB del área geográfica de estudio en la ciudad de San Luis Río Colorado, Sonora

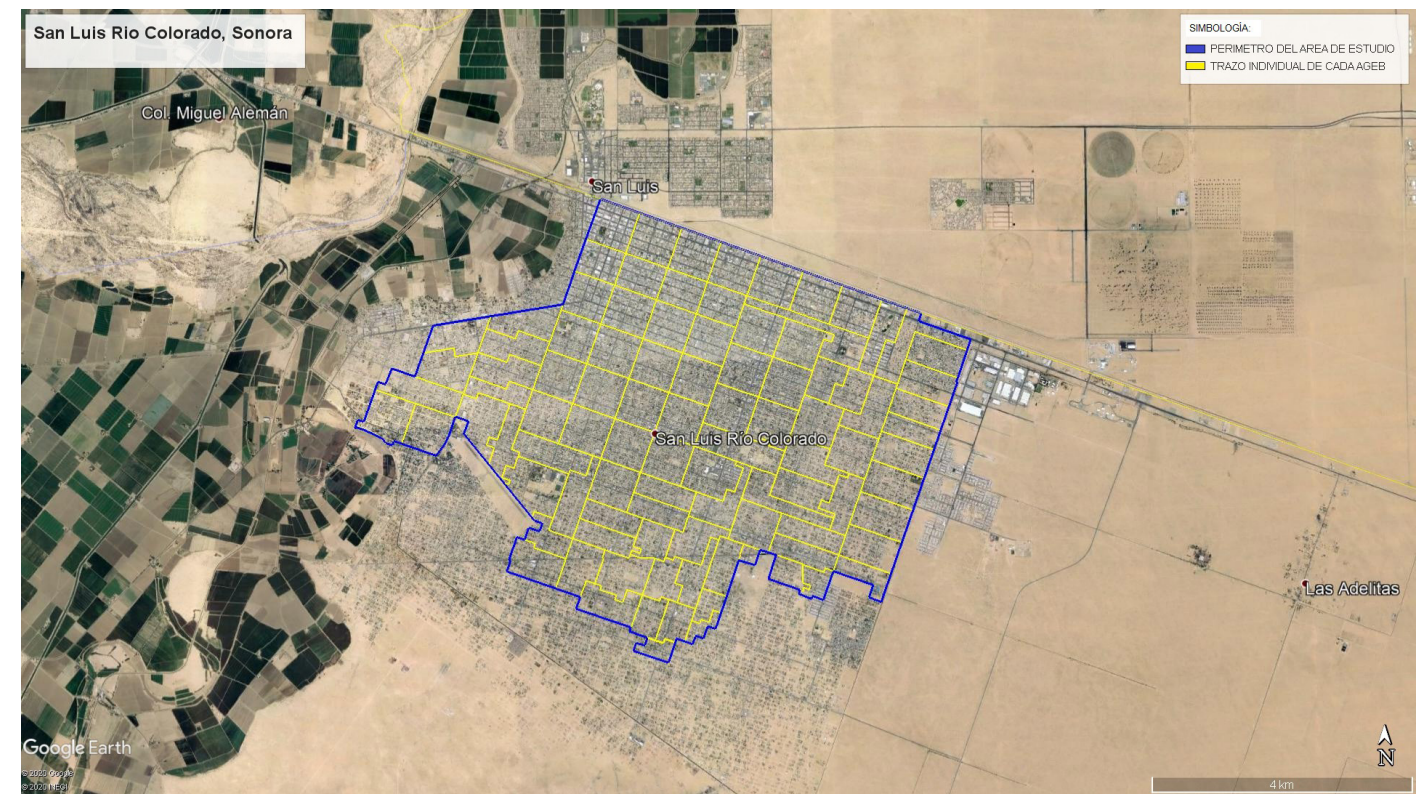

Fuente: Elaboración propia con base en información de INEGI (2018).

De esta manera, mediante la interpretación de fotografías aéreas ortogonales se realizaron levantamientos digitales en las tres ciudades analizadas, localizando casos específicos y trazando polígonos individuales de cada uno de los espacios abandonados que fueron ubicados dentro de las zonas de estudio. Paralelamente, se realizaron levantamientos físicos en campo para cotejar la información previamente obtenida en cada uno de los digitales, así como también se fotografiaron los casos más representativos. Para integrar la información obtenida se empleó un programa computacional especializado en sistemas de información geográfica (Quantum Geographic Infotmation System, QGIS) con el objetivo de generar los mapas que son objeto del presente trabajo de investigación, y, a su vez, constituir una base de datos independiente en cada una de las ciudades analizadas.

Tras el análisis e interpretación de la información contendida en cada una de las bases de datos, se generaron estadísticas sobre los porcentajes proporcionales entre las superficies de cada espacio abandonado respecto a la de cada AGEB. Además, también se calcularon los índices de densidad en cada AGEB, con el fin de conocer el número de casos de estudio que se presentaron en cada ciudad. Esta información fue empleada de forma correlacional con los rangos de pobreza expresados en el Informe de pobreza en los municipios de México 2015 (CONEVAL, 2018), haciendo un énfasis directo hacia aquellas AGEB que fueron identificadas con un rango de pobreza superior al 50\%; de esta forma, se logró conocer el comportamiento de los índices de densidad en las áreas de mayor pobreza de cada una de las tres ciudades analizadas.

EntreDiversidades. Revista de Ciencias Sociales y Humanidades, Vol. 8, Núm. 2 (17), julio-diciembre 2021. Páginas: 119-144 ISSN-e: 2007-7610. https://doi.org/10.31644/ED.V8.N2.2021.A06 
Finalmente, en este escrito se lleva a cabo una reflexión con el objetivo de generar una serie de discusiones encaminadas a realizar un análisis interurbano, enfatizando el papel que juegan los rangos de pobreza como un posible factor de influencia espacial, para de esta manera lograr exponer y buscar dar respuesta a las diferencias y similitudes encontradas entre las ciudades de Mexicali, Nuevo Laredo y San Luis Río Colorado.

\section{Criterios para la selección y clasificación de los espacios abandonados}

Es preciso señalar que en la presente investigación no se consideraron aquellas edificaciones que simplemente están temporalmente desocupadas, debido a que en cualquier momento pueden reactivarse sin necesidad de que exista un proceso formal de rehabilitación (como podría ser el ejemplo de una vivienda temporalmente deshabitada). Por tanto, se establecieron como abandonados aquellos espacios no solo deshabitados o que no fueran funcionales, sino que además también mostraran un grado de deterioro significativo. Del mismo modo, fue necesario que cumplieran con la premisa de contener ciertos rasgos de construcciones marginadas o degradadas, manifestadas en al menos el 10\% de su superficie. Así, aquellos sectores donde se presentó una gran cantidad de superficie libre, sin edificar (concretamente un porcentaje vacío superior al 90\% de su superficie), se tuvieron en cuenta como vacíos urbanos y no como espacios abandonados.

Por otra parte, la diversidad mostrada por el objeto de estudio propició la generación de una clasificación de cinco tipologías distintas de espacios abandonados: 1) viviendas, 2) comercios, 3) parques públicos y áreas de esparcimiento, 4) edificaciones de servicios públicos y 5) ruinas (ver Figura 6).

Figura 6. Clasificación que muestra las distintas tipologías de espacios abandonados

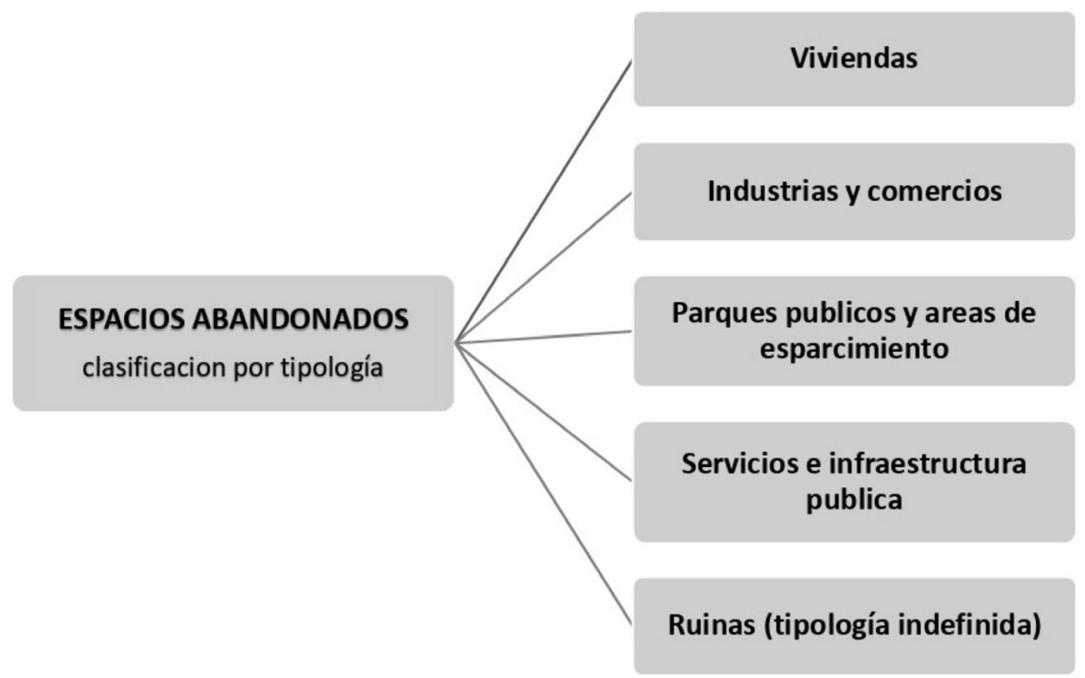

Fuente: Elaboración propia con base en los postulados teóricos expuestos por Azevedo de Sousa (2010), Shane (2012) y Curzio (2021).

EntreDiversidades. Revista de Ciencias Sociales y Humanidades, Vol. 8, Núm. 2 (17), julio-diciembre 2021. Páginas: 119-144 ISSN-e: 2007-7610. https://doi.org/10.31644/ED.V8.N2.2021.A06 
Cabe mencionar que la tipología vinculada con servicios e infraestructura pública agrupa básicamente a aquellas edificaciones, nodos de infraestructura o elementos de equipamiento urbano que poseían un carácter público y que gradualmente quedaron abandonados, como por ejemplo, oficinas gubernamentales, hospitales, escuelas, terminales de transporte, pozos hidráulicos, torres o subestaciones eléctricas, etc. Por otra parte, los espacios catalogados como "ruinas" están relacionados con aquellas construcciones que presentan un grado de deterioro tan significativo que resulta imposible lograr determinar la morfología que en algún momento llegó a poseer dicha edificación y, por lo tanto, resulta imposible asignarles alguna otra tipología.

\section{Criterios para la medición de la pobreza}

Para fines de la presente investigación se tomaron como referencia los estudios realizados por el Consejo Nacional de Evaluación de la Política de Desarrollo Social (CONEVAL), considerando específicamente los resultados obtenidos del "Informe de pobreza en los municipios de México 2015” (CONEVAL, 2018). Dicho estudio, además de abarcar todo el territorio nacional y presentar resultados a nivel estatal y municipal, cuenta con una base de datos detallada donde se exponen los resultados a nivel nacional (abarcando una totalidad 51034 AGEB). La metodología del informe, descrita en detalle en la publicación "Metodología para la medición multidimensional de la pobreza en México” (CONEVAL, 2010), retoma la visión modificada de necesidades básicas insatisfechas y su relación con el ingreso, así como también se ve fundamentada mediante la perspectiva de David Gordon (2002) respecto a su propuesta de medición de pobreza en Reino Unido. Paralelamente, el diseño metodológico tiene como objetivo identificar la condición de pobreza fundamentalmente con base en la resolución de dos ámbitos básicos expuestos por Amartya Sen (1976), el problema de la identificación y el de la agregación o medición.

Para resolver la cuestión relacionada con de la identificación de la población en situación de pobreza la metodología plantea abordar este ámbito desde dos dimensiones distintas: 1) "El de la dimensión asociada al espacio del bienestar económico, la cual se mide operativamente por el indicador de ingreso corriente per cápita", y 2) "El de las dimensiones asociadas a los derechos sociales, es decir, la educación, la salud, la seguridad social, la alimentación nutritiva y de calidad, la vivienda y sus servicios" (CONEVAL, 2010: 39). De esta manera, dicha metodología toma como parámetro la siguiente definición de pobreza:

Una persona se encuentra en situación de pobreza multidimensional cuando no tiene garantizado el ejercicio de al menos uno de sus derechos para el desarrollo social, y si sus ingresos son insuficientes para adquirir los bienes y servicios que requiere para satisfacer sus necesidades" (CONEVAL, 2010: 38).

Así, la metodología planteada por CONEVAL considera trece indicadores de incidencia de pobreza multidimensional, de bienestar o de carencia, los cuales constituyen el fundamento operativo para lograr formular rangos de pobreza específicos para cada una de las AGEB:

EntreDiversidades. Revista de Ciencias Sociales y Humanidades, Vol. 8, Núm. 2 (17), julio-diciembre 2021. Páginas: 119-144 ISSN-e: 2007-7610. https://doi.org/10.31644/ED.V8.N2.2021.A06 
1. Población con un ingreso inferior a la línea de bienestar.

2. Población con un ingreso inferior a la línea de bienestar mínimo.

3. Carencia por rezago educativo.

4. Carencia de acceso a los servicios de salud.

5. Carencia de acceso a la seguridad social.

6. Carencia por la calidad y espacios de la vivienda.

7. Carencia por servicios básicos en la vivienda.

8. Carencia de acceso a la alimentación.

9. Población con una o más carencias sociales.

10. Población con tres o más carencias sociales.

11. Población en pobreza multidimensional.

12. Población en pobreza multidimensional extrema.

13. Población en pobreza multidimensional moderada. (CONEVAL, 2010: 44).

Es importante aclarar que CONEVAL especifica que como parte de su metodología para "las mediciones de pobreza a escala municipal se utilizaron principalmente dos tipos de fuentes de información: el MCS-ENIGH, ${ }^{7}$ así como los datos de la muestra del Censo de Población y Vivienda 2010, y en 2015, de la Encuesta Intercensal. Todos estos ejercicios estadísticos fueron llevados a cabo por el Instituto Nacional de Estadística y Geografía” (CONEVAL, 2015).

\section{Análisis intraurbano de Mexicali}

En la ciudad de Mexicali fue establecida un área de estudio compuesta por la sumatoria de 151 AGEB, lo cual en términos territoriales representa una superficie equivalente a 7435.83 hectáreas. Concretamente, fueron localizados y registrados 1524 espacios abandonados, lo que representa un índice de densidad de 0.20 casos por cada hectárea. Paralelamente, también fue posible precisar la sumatoria de cada una de las superficies individuales de todos los espacios abandonados, resultando en un total de 65.78 hectáreas, equivalente al $0.88 \%$ del área de estudio analizada.

La sumatoria de cada una de las superficies individuales fue dividida entre la totalidad de casos registrados, y de esta forma se determinó que el tamaño de la superficie promedio de los espacios abandonados en la ciudad de Mexicali es de $431.73 \mathrm{~m}^{2}$. Así mismo, fue posible identificar que 563 casos (el 36.94\%) pertenecen a una escala reducida, ya que cuentan con una superficie inferior a $200 \mathrm{~m}^{2}$, mientras que 748 casos (el $49.08 \%$ ) son considerados dentro del parámetro de escala intermedia, con un área entre el rango de $200 \mathrm{~m}^{2}$ y $500 \mathrm{~m}^{2}$. Finalmente, solo 213 casos (el $13.98 \%$ ) son de gran escala, con una superficie superior a los $500 \mathrm{~m}^{2}$.

Con lo que respecta al tema de la pobreza, analizando los rangos establecidos por CONEVAL (2015) en cada una de las 151 AGEB, fue posible determinar que en el área de estudio existe un rango de pobreza del $21.58 \%$, y únicamente 6 AGEB cuentan con un rango de pobreza superior

${ }^{7}$ Módulos de Condiciones Socioeconómicas de la Encuesta Nacional de Ingresos y Gastos de los Hogares.

EntreDiversidades. Revista de Ciencias Sociales y Humanidades, Vol. 8, Núm. 2 (17), julio-diciembre 2021. Páginas: 119-144 ISSN-e: 2007-7610. https://doi.org/10.31644/ED.V8.N2.2021.A06 
al 50\% (ver áreas en color amarillo en Figura 7). Sin embargo, tan solo 55 espacios abandonados estuvieron localizados dentro de esas zonas de mayor marginación; en términos porcentuales esto representa apenas el 3.61\% del total de casos, en cambio, en estas 6 AGEB existe un índice de densidad de 0.31 casos por cada hectárea. En contraposición, un significativo número total de 921 casos fueron localizados en las AGEB calificadas con el menor rango de pobreza (inferior al rango del 26\%), lo cual en términos porcentuales representa el $60.43 \%$ del total de casos; aun así, en dichas AGEB el índice de densidad correspondió únicamente a 0.19 casos por cada hectárea.

Estos resultados muestran que las AGEB con mayor rango de pobreza tienen un índice de densidad más alto de espacios abandonados, sin embargo, la correspondencia a nivel espacial no resulta del todo concluyente, debido a que los principales patrones de aglomeración no se presentaron propiamente en las AGEB más marginadas; esta situación también queda de manifiesto cuando se analiza el modelo espacial (ver Figura 7).

\section{Figura 7. Distribución de los 1524 espacios abandonados localizados en Mexicali}

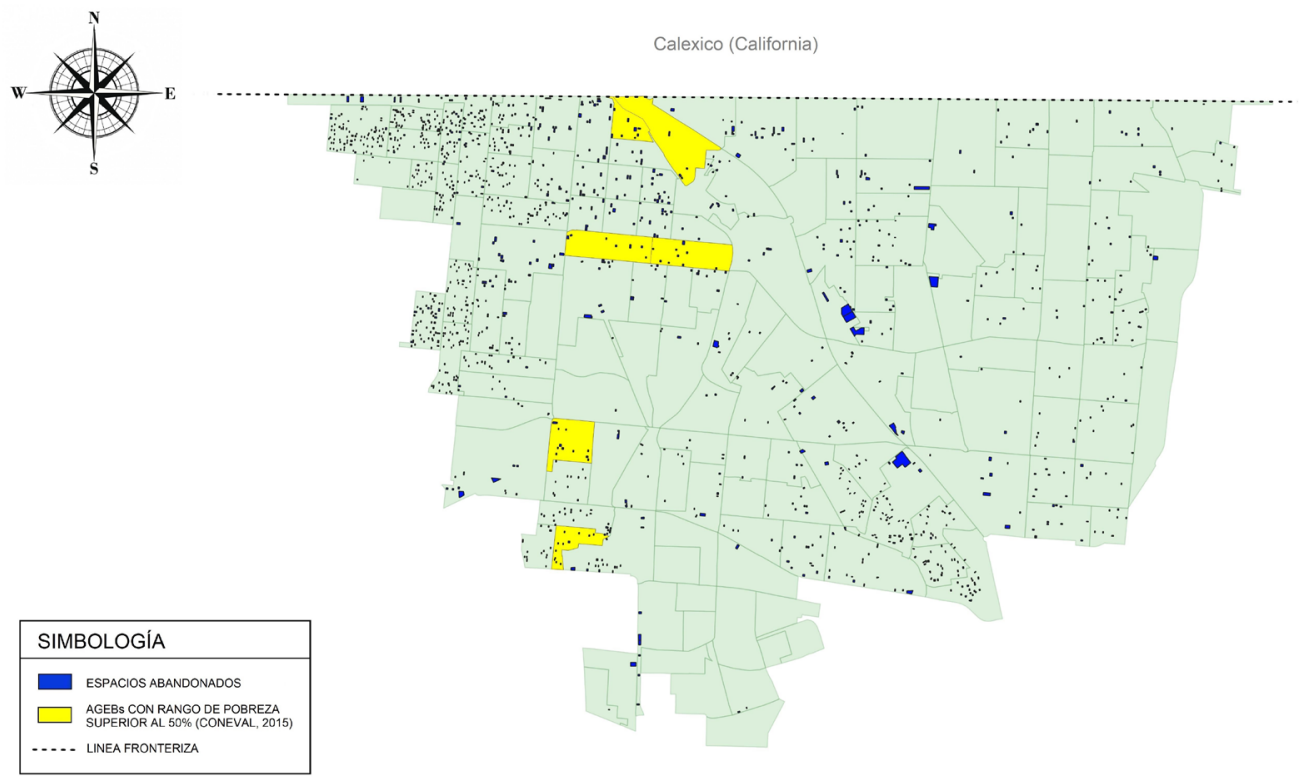

Modelo espacial que muestra la distribución de los 1524 espacios abandonados localizados en la ciudad de Mexicali, en color amarillo pueden identificarse las AGEB con mayor rango de pobreza (superior al 50\%). Fuente: Elaboración propia con base en información documental.

En el anterior modelo es posible observar que la distribución espacial de las ubicaciones abandonadas en la ciudad de Mexicali responde a patrones de aglomeración plenamente definidos, concretamente existe una muy clara concentración hacia el área norponiente de la ciudad,

EntreDiversidades. Revista de Ciencias Sociales y Humanidades, Vol. 8, Núm. 2 (17), julio-diciembre 2021. Páginas: 119-144 ISSN-e: 2007-7610. https://doi.org/10.31644/ED.V8.N2.2021.A06 
muy cerca del principal cruce fronterizo hacia Calexico, específicamente en los barrios Pueblo Nuevo, Santa Clara, Lucerna y Revolución. Así mismo, en la zona sur de la ciudad también se encuentran algunas aglomeraciones en los barrios Hidalgo y Xochimilco. En contraparte, visualmente también se aprecia que la zona oriente de la ciudad presenta claramente un grado de concentración muy distinta respecto a lo que sucede en la zona poniente, ya que es posible observar una menor cantidad de casos.

\section{Análisis intraurbano de Nuevo Laredo}

En el caso de Nuevo Laredo se estableció un área de estudio compuesta por la sumatoria de 110 AGEB, lo cual en términos territoriales representa una superficie equivalente a 4597.87 hectáreas. En específico, en el interior de dicho polígono fueron localizados y registrados un total de 1086 espacios abandonados, que suponen un índice de densidad equivalente a 0.24 casos por cada hectárea. A su vez, también se determinó la suma de las superficies individuales de todos los espacios abandonados, resultando en un total de 41.63 hectáreas, equivalente al $0.91 \%$ del área de estudio analizada.

Considerando la sumatoria de cada superficie individual y dividiéndola entre la totalidad de casos registrados, se estableció que el tamaño de la superficie promedio de los espacios abandonados en la ciudad de Nuevo Laredo es de $383.33 \mathrm{~m}^{2}$, y que 496 casos (el 45.67\%) se engloban en una escala reducida, ya que cuentan con una superficie inferior a $200 \mathrm{~m}^{2}$, mientras que 412 casos (el 37.94\%) son considerados dentro del parámetro de escala intermedia, con un área entre el rango de los $200 \mathrm{~m}^{2}$ y $500 \mathrm{~m}^{2}$. Por último, en total 178 casos (el 16.39\%) se estiman como de gran escala, ya que cuentan con una superficie superior a los $500 \mathrm{~m}^{2}$.

Analizando los rangos establecidos por CONEVAL (2015) en cada una de las 110 AGEB, se determinó que en el área de estudio existe un rango de pobreza del 34.22\%, específicamente 22 AGEB cuentan con un rango de pobreza superior al 50\% (ver áreas en color amarillo en Figura 8), con un total de 405 espacios abandonados localizados en las mismas, lo que representa el $37.29 \%$ del total de casos; además, en dichas AGEB existe un índice de densidad de 0.52 casos por cada hectárea. Por otro lado, tan solo 237 casos fueron localizados en las AGEB calificadas con un menor rango de pobreza (inferior al rango del $26 \%$ ), lo cual en términos porcentuales significa el 21.82\% del total de casos; del mismo modo, en dichas AGEB únicamente se presentó un índice de densidad de únicamente 0.11 casos por cada hectárea.

Estos resultados manifiestan que las amplias diferencias entre los índices de densidad responden a una prevalencia de los espacios abandonados hacia las AGEB con mayor rango de pobreza; esta situación también queda de manifiesto cuando se analiza el comportamiento del modelo espacial (ver Figura 8).

EntreDiversidades. Revista de Ciencias Sociales y Humanidades, Vol. 8, Núm. 2 (17), julio-diciembre 2021. Páginas: 119-144 ISSN-e: 2007-7610. https://doi.org/10.31644/ED.V8.N2.2021.A06 
Figura 8. Distribución de los 1086 espacios abandonados localizados en Nuevo Laredo
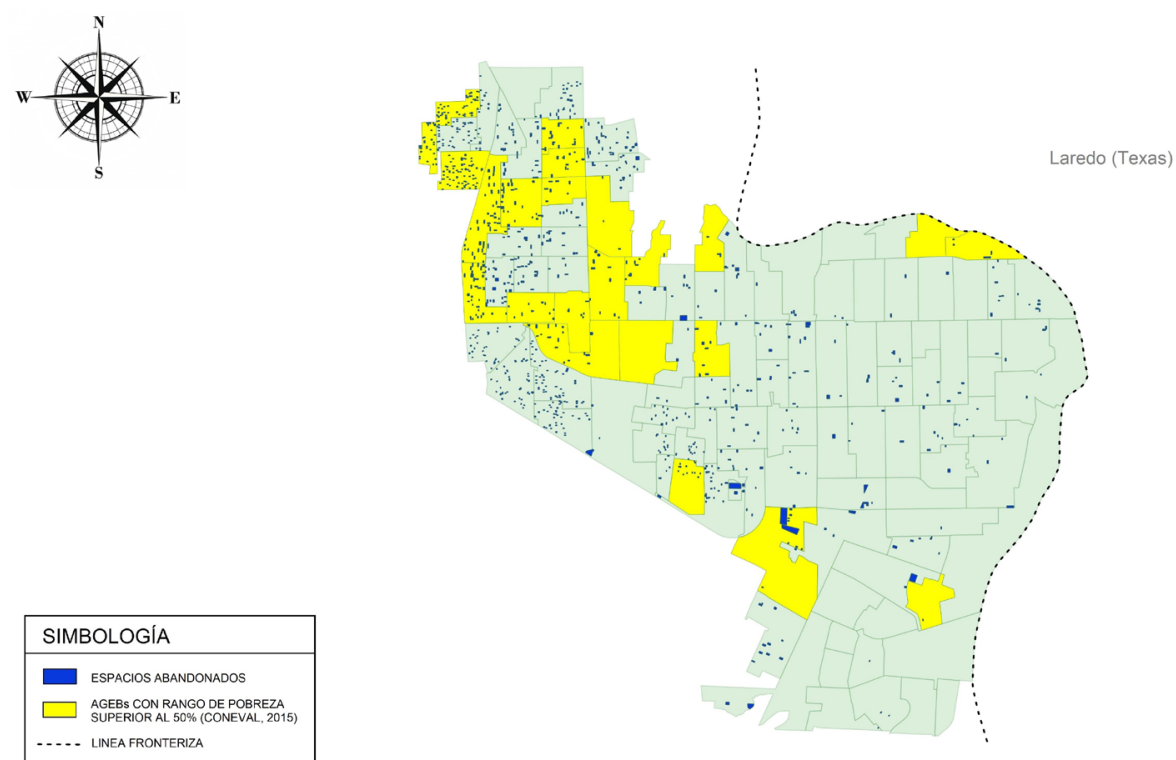

Modelo espacial que muestra la distribución de los 1086 espacios abandonados localizados en la ciudad de Nuevo Laredo, en color amarillo pueden identificarse las AGEB con mayor rango de pobreza (superior al 50\%). Fuente: Elaboración propia con base en información documental.

El modelo espacial permitió identificar de manera visual que efectivamente existen patrones de aglomeración definidos en Nuevo Laredo, concretamente se percibe una concentración claramente definida hacia el área norponiente de la ciudad, específicamente en los barrios Bellavista, Bertha del Arellano, Buenavista, Voluntad y Trabajo, Los Garza y La Joya. Por el contrario, visualmente se puede apreciar que las zonas más cercanas a la frontera presentan la menor cantidad de casos.

\section{Análisis intraurbano en San Luis Río Colorado}

En la ciudad de San Luis Río Colorado se estableció un área de estudio compuesta por la sumatoria de 97 AGEB, lo cual en términos territoriales representa una superficie de 3686.47 hectáreas. En el interior de dicho polígono fueron localizados y registrados un total de 1787 espacios abandonados, que cuentan con un índice de densidad de 0.48 casos por cada hectárea. El resultado total de la suma de las superficies individuales de todos los espacios abandonados es de 91.69 hectáreas, es decir, el 2.49\% del área de estudio analizada.

Tomando como base la sumatoria individual de cada superficie y dividiéndola entre la totalidad de casos registrados, se determinó que la superficie promedio de los espacios abandonados de la ciudad es de $513.11 \mathrm{~m}^{2}$. Así, en San Luis Río Colorado se identifican únicamente 23 casos

EntreDiversidades. Revista de Ciencias Sociales y Humanidades, Vol. 8, Núm. 2 (17), julio-diciembre 2021. Páginas: 119-144 ISSN-e: 2007-7610. https://doi.org/10.31644/ED.V8.N2.2021.A06 
(el $1.29 \%$ ) correspondientes a una escala menor, con una superficie inferior a $200 \mathrm{~m}^{2}$. En contraposición, 1157 casos (el 64.75\%) pertenecen al parámetro de escala intermedia (área entre el rango de los $200 \mathrm{~m}^{2}$ y $500 \mathrm{~m}^{2}$ ). Finalmente, 607 casos (el 33.97\%) son de gran escala (superficie superior a los $500 \mathrm{~m}^{2}$ ).

Tras el análisis de los rangos establecidos por CONEVAL (2015) en cada una de las 97 AGEB se pudo concretar que en el área de estudio existe un rango de pobreza del $38.40 \%$, específicamente, 20 AGEB cuentan con un rango de pobreza superior al 50\% (ver áreas en color amarillo en Figura 9), con un total de 441 espacios abandonados —en términos porcentuales esto representa el 24.68\% del total de casos-; del mismo modo, en dichas AGEB existe un índice de densidad de 0.65 casos por cada hectárea. A su vez, 589 casos fueron localizados en las AGEB calificadas con un menor rango de pobreza (inferior al rango del $26 \%$ ), lo cual en términos porcentuales significa el 32.96\% del total de casos; sin embargo, en dichas AGEB se presentó un índice de densidad de 0.38 casos por cada hectárea.

Por tanto, estos resultados muestran que las AGEB con mayor rango de pobreza tienen claramente un mayor índice de densidad, sin embargo, la repartición de los casos de estudio también evidencia que existe una presencia relativamente homogénea de espacios abandonados en prácticamente todas las zonas de la ciudad (no solo en las de mayor pobreza); esta situación también se ve reflejada cuando se analiza el modelo espacial (ver Figura 9).

\section{Figura 9. Distribución de los 1787 espacios abandonados localizados en San Luis Río Colorado}

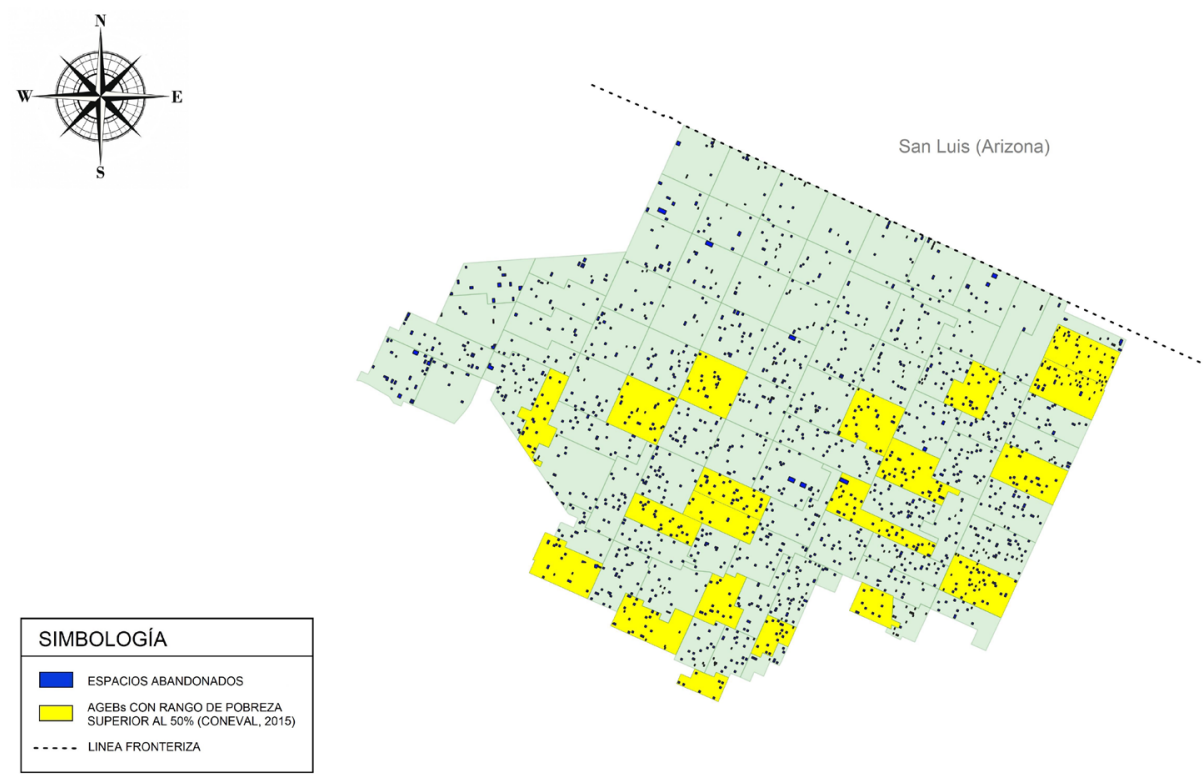

Modelo espacial que muestra la distribución de los 1787 espacios abandonados localizados en la ciudad de San Luis Río Colorado, en color amarillo pueden identificarse las AGEB con mayor rango de pobreza (superior al 50\%). Fuente: Elaboración propia con base en información documental.

EntreDiversidades. Revista de Ciencias Sociales y Humanidades, Vol. 8, Núm. 2 (17), julio-diciembre 2021. Páginas: 119-144 ISSN-e: 2007-7610. https://doi.org/10.31644/ED.V8.N2.2021.A06 
Con respecto al análisis espacial de la distribución de los casos de estudio en San Luis Río Colorado, es posible identificar de manera visual que no se perciben significativas tendencias en cuanto a patrones de aglomeración, sino que, por el contrario, existe una dispersión aleatoria e independiente. Algunas ligeras tendencias de densidad pueden observarse en la zona poniente de la ciudad, donde aparecen una menor intensidad de casos, mientras que hacia el oriente se incrementan; concretamente, esto se observa en los barrios Campestre, Altar y Progreso. Así mismo, visualmente también se aprecia que en las zonas más próximas a la frontera existe una menor intensidad de cantidad de espacios abandonados.

\section{Análisis comparativo a nivel interurbano}

Tras haber descrito los resultados en las ciudades de Mexicali, Nuevo Laredo y en San Luis Río Colorado, se presenta un debate encaminado a describir los principales hallazgos que surgieron al contrastar las diferencias detectadas en cada una de las ciudades, tomando como eje rector de la discusión la distribución geo-espacial y su vinculación con el tema de la pobreza. Para facilitar esta labor, a continuación se presenta el siguiente apéndice que integra los resultados de las tres ciudades (ver Tabla 2).

Tabla 2. Apéndice con la integración de resultados

\begin{tabular}{|c|c|c|c|c|}
\hline & & Mexicali & Nuevo Laredo & $\begin{array}{l}\text { San Luis Río } \\
\text { Colorado }\end{array}$ \\
\hline \multirow{3}{*}{$\begin{array}{l}\text { Información } \\
\text { del área de } \\
\text { estudio }\end{array}$} & Numero de AGEBS & 151 & 110 & 97 \\
\hline & Superficie total & $7,435.83$ & $4,597.87$ & $3,686.47$ \\
\hline & Rango de pobreza (CONEVAL, 2015) & $21.58 \%$ & $34.22 \%$ & $38.40 \%$ \\
\hline \multirow{5}{*}{$\begin{array}{l}\text { Información } \\
\text { descriptiva de } \\
\text { los espacios } \\
\text { abandonados }\end{array}$} & Total de casos localizados & 1524 & 1086 & 1787 \\
\hline & Índice de densidad (casos por hectárea) & 0.20 & 0.24 & 0.48 \\
\hline & Sumatoria de superficies individuales & 65.78 & 41.63 & 91.69 \\
\hline & Porcentaje respecto al área de estudio & $0.88 \%$ & $0.91 \%$ & $2.49 \%$ \\
\hline & Tamaño promedio & 431.63 & 383.33 & 513.09 \\
\hline \multirow{7}{*}{$\begin{array}{c}\text { Información } \\
\text { de variables } \\
\text { relacionadas con } \\
\text { la pobreza }\end{array}$} & $\begin{array}{l}\text { Casos en AGEB con altos rangos de pobreza } \\
\text { (superior al } 50 \% \text { ) }\end{array}$ & 55 & 405 & 441 \\
\hline & Porcentaje respecto al total de casos & $3.61 \%$ & $37.29 \%$ & $24.68 \%$ \\
\hline & $\begin{array}{l}\text { Casos en AGEB con bajos rangos de pobreza } \\
\text { (inferiores al 26\%) }\end{array}$ & 921 & 237 & 589 \\
\hline & Porcentaje respecto al total de casos & $60.43 \%$ & $21.82 \%$ & $32.96 \%$ \\
\hline & $\begin{array}{l}\text { Índice de densidad de casos en AGEBS con altos } \\
\text { rangos de pobreza (superior al } 50 \% \text { ) }\end{array}$ & 0.31 & 0.52 & 0.65 \\
\hline & $\begin{array}{l}\text { Índice de densidad de casos en AGEBS con bajos } \\
\text { rangos de pobreza (inferior al } 26 \% \text { ) }\end{array}$ & 0.19 & 0.11 & 0.38 \\
\hline & Diferencia resultante entre ambos índices de densidad & +0.12 & +0.41 & +0.27 \\
\hline
\end{tabular}

Fuente: Elaboración propia con base en información documental. 
De esta forma, los principales hallazgos son los siguientes:

1. Una diferencia significativa entre las ciudades se da con relación a los índices de densidad de los espacios abandonados detectados. La respuesta puede encontrarse vinculada a la escala de cada ciudad, en términos de las oportunidades laborales y de la diversidad de actividades económicas que cada una de las urbes puede ofrecer. En ese sentido, San Luis Río Colorado es la ciudad que presenta el índice de densidad más alto ( 0.48 espacios abandonados por cada hectárea), el mayor coeficiente de superficie (2.49\% del total del área de estudio) y, además, es el área de estudio que muestra el rango de pobreza más elevado (38.40\%). Estos resultados pueden encontrar sentido cuando se reflexiona en torno a que dicha ciudad no cuenta con un sector industrial diversificado ni especializado, lo cual lleva a que la fuerza de trabajo tenga que desplazarse a otras ciudades en busca de nuevas oportunidades; básicamente ocurre una movilidad (generalmente transfronteriza) que se traduce en una migración de sus habitantes, lo cual trae como consecuencia el abandono de diversos espacios (viviendas, comercios, industrias, áreas verdes, etc.).

2. Con respecto a la correlación espacial vinculando el tema de la pobreza, en las tres ciudades analizadas es posible observar que coincidentemente hay una diferencia significativa en los índices de densidad de espacios abandonados entre las AGEB con mayor rango de pobreza (superior al 50\%) respecto de las AGEB con menor rango (inferior al 26\%), lo cual indica que las áreas de mayor pobreza son también las que presentan un mayor coeficiente de densidad de espacios abandonados. Sin embargo, al momento de analizar los modelos espaciales los resultados fueron contrastantes en cuanto a que en el caso de Nuevo Laredo y San Luis Río Colorado existe una correspondencia espacial entre las AGEB con mayor rango de pobreza y los patrones de aglomeración de los espacios abandonados, pero, en el caso de Mexicali no es posible percibir dicha coincidencia; lo anterior puede deberse a que en el área analizada de dicha ciudad existen muy pocas AGEB que pertenezcan a la categoría del rango de pobreza alto (superior al 50\%), únicamente el $3.97 \%$ de las AGEB analizadas.

3. Como resultado del análisis geo-espacial se detecta la existencia de un menor número de espacios abandonados en las zonas más próximas a la frontera. La respuesta a este fenómeno puede deberse a que comúnmente hay una mayor plusvalía en los sectores más cercanos a la franja fronteriza, es decir, son mucho más deseables para habitar y principalmente para establecer comercios, situación que no suele ser desaprovechada, por lo que bajo esa lógica es comprensible que existan pocos espacios abandonados. Cabe aclarar que una única excepción se presentó en la colonia Pueblo Nuevo, localizada en el límite fronterizo de la ciudad de Mexicali. Concretamente, el número alto índice de espacios abandonados podría encontrar significado debido a flujos migratorios que se vieron altamente fomentados con la implementación del programa "Bracero", un programa binacional implementado entre 1942 y 1964, que tuvo por objetivo impulsar el cruce legal y temporal de alrededor de 4.5 millones de trabajadores provenientes de México a Estados Unidos.

4. En relación con la naturaleza de los patrones de aglomeración, en el caso de Mexicali y Nuevo Laredo se observa una distribución espacial caracterizada por su heterogeneidad, es decir, existen sectores muy específicos donde se concentran el mayor número de casos de estudio,

EntreDiversidades. Revista de Ciencias Sociales y Humanidades, Vol. 8, Núm. 2 (17), julio-diciembre 2021. Páginas: 119-144 ISSN-e: 2007-7610. https://doi.org/10.31644/ED.V8.N2.2021.A06 
contrastando con otras áreas de la ciudad donde realmente resulta insignificante el número de casos. Sin embargo, en cuanto a San Luis Río Colorado se precia un comportamiento espacial muy distinto, ya que la distribución de los casos de estudio se presenta de una manera bastante homogénea. La respuesta a esta gran diferencia podría estar íntimamente vinculada con la escala de la ciudad. De este modo, en una ciudad de mayor tamańo, como serían los casos de Mexicali y Nuevo Laredo, existen una mayor variedad de barrios habitacionales, lo cual puede traducirse en una segregación de clases sociales, es decir, de una forma muy evidente la población se ha ido distribuyendo dependiendo de su nivel socio-económico, lo cual se ve expresado en la conformación de barrios de alto nivel en donde es poco probable que surja un espacio abandonado. En contraparte, San Luis Río Colorado es una población más reducida, donde realmente no resulta tan notable esa segregación de clases a nivel socio-económico, situación que se refleja en cuanto a que la población se distribuye de una forma homogénea dentro de dicha ciudad y, por lo tanto, los sectores más marginados no se concentran en puntos específicos.

5. De forma muy particular, se hallan resultados contrastantes al momento de analizar y comparar las densidades de concentración entre la periferia y el núcleo urbano plenamente consolidado en las tres áreas de estudio. Así, Nuevo Laredo se conforma como la única ciudad que realmente muestra una clara tendencia de espacios abandonados con mayor presencia en los bordes urbanos, es decir, en las áreas periféricas — las cuales frecuentemente suelen estar caracterizadas por contener barrios que están en proceso de desarrollo o bien presentan un mayor grado de marginación socio-económica-. Sin embargo, en el caso de Mexicali y San Luis Río Colorado no se aprecia una mayor densidad de espacios abandonados en las periferias. Probablemente la explicación a esta diferencia podría lograrse mediante un análisis detallado y cronológico enfocado en la evolución de la morfología urbana de cada una de las ciudades, con el objetivo de reflexionar en torno a cómo se ha venido configurando su expansión territorial.

\section{Conclusiones}

Los espacios abandonados se caracterizan por el hecho de contar con una ocupación previa con un uso específico, cuya función ahora ya no cumplen, pese a seguir delimitados e inmersos en las estructuras urbanas de una determinada ciudad. Este proceso debe ser comprendido desde una óptica de constante transformación de las estructuras urbanas, impulsada principalmente por factores sociales, económicos y políticos. De esta manera, en el presente artículo se expone cómo la pobreza puede ser comprendida como una posible consecuencia del surgimiento de este tipo de espacios. Sin embargo, más allá de esta causalidad, también se conjugan otro tipo de factores relacionados con la migración y la movilidad de la población que podrían ofrecer otras explicaciones a la conformación de espacios abandonados en las ciudades, ya que cada vez resulta más frecuente observar la falta de correspondencia entre el lugar donde habita la fuerza de trabajo y el sitio donde se localizan los empleos. Por tanto, comprender el papel que juega la migración resulta de vital importancia para poder realizar un análisis integral sobre cómo surgen este tipo de espacios, los cuales en gran medida también son un reflejo de la pérdida de actividades comerciales e industriales en ciudades fronterizas.

EntreDiversidades. Revista de Ciencias Sociales y Humanidades, Vol. 8, Núm. 2 (17), julio-diciembre 2021. Páginas: 119-144 ISSN-e: 2007-7610. https://doi.org/10.31644/ED.V8.N2.2021.A06 
La gran cantidad de casos de estudios registrados obliga a reflexionar en cuanto a la necesidad de modificar la forma en que los espacios abandonados se presentan ante los habitantes y, especialmente, ante las personas encargadas de tomar decisiones a nivel de política urbana, inclusive con relación a futuras líneas de investigación que pudiesen estar encaminadas a replantear las normatividades legales, con el objetivo de encontrar soluciones para que las autoridades puedan implementar acciones regenerativas sobre aquellos lugares inutilizados de propiedad privada. Concretamente, deben ser reconocidos como espacios marginales, con la finalidad de prevenir la diversidad de conflictos que sin duda pueden llegar a crear en su entorno inmediato, pero, al mismo tiempo, también es importante fomentar que sean vistos como elementos urbanos de oportunidad que contienen un gran potencial para impulsar cambios que regeneren las estructuras urbanas y, con ello, lograr mejorar la calidad de vida de los habitantes.

En síntesis, el presente artículo contribuye a proponer un diseño metodológico especializado en lograr comprender cuál es la distribución geográfica que presentan los espacios abandonados y cómo es que pueden analizarse desde distintas variables sociales; en este caso, el presente análisis se concentró específicamente en algunas dimensiones de la pobreza, sin embargo, se tornan necesarias futuras líneas de investigación vinculadas con otros aspectos socio-económicos de la población para alcanzar una visión más amplia. Dichos estudios podrían ir acompañados de resultados que se deriven del uso de diversas técnicas de análisis geo-espacial, sin embargo, estas deben ser vistas únicamente como una herramienta que complemente la formulación de propuestas de rehabilitación integrales, incluyendo diversos tipos de consideraciones antrópicas (como por ejemplo, la historia del lugar o la diversidad cultural de su población). Particularmente, en el caso de las ciudades fronterizas, también resultaría interesante considerar como una posible línea de investigación el lograr valorar y estudiar con mayor profundidad cuál es el peso que pueden llegar a tener los procesos migratorios sobre la proliferación de este tipo de espacios abandonados.

\section{Bibliografía citada}

Anderson, Joan B., y Gerber, James (2007). Fifty Years of Change on the U.S.-Mexico Border: Growth, Development, and Quality of Life. Texas, United States of America: University of Texas Press.

Azevedo de Sousa, Claudia (2010). Do cheio para o vazio. Metodologia e estratégia na avaliação de espaços urbanos obsoletos. Tesis para obtener el grado de Maestría en Arquitectura. Instituto Superior Técnico, Universidad Politécnica de Lisboa. Disponible en: https:// fenix.tecnico.ulisboa.pt/downloadFile/395142195938/DO\%20CHEIO\%20PARA\%20 O\%20VAZIO versao\%20final.pdf (Consultado el 5 de septiembre de 2009).

Castillo Ramírez, Guillermo, y González, Jorge (2020). "Cambios espaciales y socioeconómicos en la migración mexicana a Estados Unidos a inicios del siglo XXI (1994-2007)”. Boletín de la Asociación de Geógrafos Españoles [en línea], Núm. 85, pp. 1-36. doi: https://doi. org/10.21138/bage.2847 (Consultado el 1 de agosto de 2020).

EntreDiversidades. Revista de Ciencias Sociales y Humanidades, Vol. 8, Núm. 2 (17), julio-diciembre 2021. Páginas: 119-144 ISSN-e: 2007-7610. https://doi.org/10.31644/ED.V8.N2.2021.A06 
Ceniceros, Brenda, y Ettinger, Catherine (2020). "Paisaje urbano desde la frontera Juárez-El Paso. Mapeando manifestaciones de arte urbano desde el bordo". EURE. Revista Latinoamericana de Estudios Urbano Regionales [en línea], 46 (137), pp. 181-201. Disponible en: http:// www.eure.cl/index.php/eure/article/view/2896 (Consultado el 5 de septiembre de 2020). Cléments, Gilles (2007). Manifiesto del Tercer Paisaje. Barcelona, Espańa: Gustavo Gili.

Consejo Nacional de Evaluación de la Política de Desarrollo Social (CONEVAL) (2010). Metodología para la medición multidimensional de la pobreza en México [en línea]. Ciudad de México, México: Consejo Nacional de Evaluación de la Política de Desarrollo Social. También disponible en: https://www.coneval.org.mx/Medicion/MP/Paginas/ Metodologia.aspx (Consultado el 23 de noviembre de 2019).

Consejo Nacional de Evaluación de la Política de Desarrollo Social (CONEVAL) (2015). Medición de la pobreza. Pobreza a nivel municipio 2010 y 2015 [en línea]. Disponible en: https://www.coneval.org.mx/Medicion/Paginas/Pobreza-municipal.aspx (Consultado el 11 de agosto de 2021).

Consejo Nacional de Evaluación de la Política de Desarrollo Social (CONEVAL) (2018). Informe de pobreza en los municipios de México 2015 [en línea]. Ciudad de México, México: Consejo Nacional de Evaluación de la política de Desarrollo Social. Disponible en: https://www.coneval.org.mx/InformesPublicaciones/Paginas/Informepobreza-municipios-Mexico-2015.aspx (Consultado el 1 de agosto de 2020).

Coubés, Marie-Laure (2003). "Evolución del empleo fronterizo en los noventa. Efectos del TLCAN y de la devaluación sobre la estructura ocupacional”. Frontera Norte [en línea], 15 (30), pp. 33-64. doi: https://doi.org/10.17428/rfn.v15i30.1512 (Consultado el 5 de marzo de 2019).

Curzio, Claudio. (2008). "El origen y las características de los fragmentos urbano-públicos residuales". Cuadernos Geograficos [en línea], Vol. 42, pp. 53-82 Disponible en: https:// revistaseug.ugr.es/index.php/cuadgeo/article/view/1132 (Consultado el 3 de febrero de 2019).

Curzio, Claudio (2021). "Redefiniendo el concepto del anti-espacio urbano: análisis enfocado en la ciudad de Nuevo Laredo". Revista cientifica de Arquitectura y Urbanismo [en línea], 42 (1), pp. 48-61. Disponible en: https://rau.cujae.edu.cu/index.php/revistaau/article/ view/605 (Consultado el 18 de enero de 2021).

Díaz-Bautista, Alejandro (2003). "El TLCAN y el crecimiento económico de la frontera norte de México”. Comercio exterior [en línea], 53 (12), pp. 1090-1097. Disponible en: http:// revistas.bancomext.gob.mx/rce/magazines/60/2/RCE.pdf (Consultado el 3 de julio de 2019).

Díaz Cruz, Nataly Alexandra (2016). "Paisaje residual en Bogotá: análisis del deterioro urbano. Ejes de Transmilenio. Avenidas El Dorado, Fernando Mazuera, Caracas y Norte Quito Sur". Revista Ciudades, Estados y Política [en línea], 3 (1), pp. 9-24. Disponible en: https:// revistas.unal.edu.co/index.php/revcep/article/view/51582 (Consultado el 19 de octubre de 2020).

EntreDiversidades. Revista de Ciencias Sociales y Humanidades, Vol. 8, Núm. 2 (17), julio-diciembre 2021. Páginas: 119-144 ISSN-e: 2007-7610. https://doi.org/10.31644/ED.V8.N2.2021.A06 
Espósito-Galarce, Fernando y Coutinho M. da Silva, Rachel (2016). "Apropiación, uso y abandono de los espacios residuales provocados por el teleférico del Complexo do Alemão, Río de Janeiro”. Arquitetura Revista [en línea], 12 (1), pp. 11-23. doi: https:// doi.org/10.4013/arq.2016.121.02 (Consultado el 4 de abril de 2020).

Garduño, Everardo (2016). "La frontera norte de México: Campo de desplazamiento, interacción y disputa”. Frontera Norte [en línea], 28 (55), pp. 131-151. doi: https://doi.org/10.17428/ rfn.v28i55.194 (Consultado el 16 de agosto de 2019).

Garza-Rodríguez, Jorge (2016). "Los determinantes de la pobreza en los estados mexicanos en la frontera con Estados Unidos". Estudios Fronterizos [en línea], 17 (33), pp. 1-19. doi: https://doi.org/10.21670/ref.2016.33.a06 (Consultado el 7 enero de 2020).

Gordon, David (2002). "The International Measurement of Poverty and Anty-Poverty Policies", en Townsend, Peter y Gordon, David (Eds.). World Poverty: New Policies to Defeat an Old Enemy. Bristol, United Kingdom: The Policy Press, pp. 53-80. También disponible en: https://doi.org/10.2307/j.ctt1t89ggq.8

Instituto Nacional de Estadística y Geografía (INEGI) (2018). Marco Geoestadistico [en línea]. Disponible en: https://inegi.org.mx/app/biblioteca/ficha.html?upc=889463674658 (Consultado el 28 de diciembre de 2018).

Instituto Nacional de Estadística y Geografía (INEGI) (2021). Datos. Áreas Geográficas [en línea]. Disponible en: https://www.inegi.org.mx/datos/\#Areas geograficas (Consultado el 5 de mayo de 2021).

Lara Cisneros, Gerardo (2011). Historia, región y frontera norte de México. Tamaulipas, México: Bonilla Artigas.

Melelli, Alberto (2012). "Áreas abandonadas y recualificación urbana. Ejemplos en Umbria (Italia)". Espacio y Tiempo. Revista de Ciencias Humanas [en línea], Núm. 26, pp. 9-26. Disponible en: https://dialnet.unirioja.es/servlet/articulo?codigo=3966581 (Consultado el 5 de febrero de 2020).

Muñoz, Francesc (2005). "Paisajes banales: Bienvenidos a la sociedad del espectaculo", en SolàMorales, Ignasi de y Costa, Xavier (Eds.). Metrópolis: ciudades, redes, paisajes. Barcelona, España: Gustavo Gili.

Nefs, Merten (2006). "Unused Urban Space: Conservation or Transformation? Polemics about the Future of Urban Wastelands and Abandoned Buildings". City \& Time [en línea], 2 (1), pp. 47-58. Disponible en: http://www.ceci-br.org/novo/revista/docs2005/CT2005-42.pdf (Consultado el 20 de diciembre de 2019).

Peimbert, Alejandro José (2016). Paisaje intersticial: vacíos y ruinas en el arte, la arquitectura y la ciudad. Universidad Autónoma de Baja California.

Pick, James B., Nanda Viswanathan y James Hettrick (2001). "The U.S.-Mexican Borderlands Region: A Binational Spatial Analysis". The Social Science Journal [en línea], 38 (4), pp. 567-592. doi: https://doi.org/10.1016/S0362-3319(01)00152-5 (Consultado el 6 de junio de 2020).

Real Academia Española (RAE) (2019). Diccionario de la lengua española [en línea]. Disponible en: https://dle.rae.es/residuo (Consultado el 17 de enero de 2019).

EntreDiversidades. Revista de Ciencias Sociales y Humanidades, Vol. 8, Núm. 2 (17), julio-diciembre 2021. Páginas: 119-144 ISSN-e: 2007-7610. https://doi.org/10.31644/ED.V8.N2.2021.A06 
Sen, Amartya (1976). "Poverty: An Ordinal Approach to Measurement". Econometrica [en línea], 44 (2), pp. 219-231. doi: https://doi.org/10.2307/1912718 (Consultado el 5 de noviembre de 2020).

Shane, Jon M. (2012). Abandoned Buildings and Lots. United States of America: Center for problem-oriented policing. Disponible en: https://popcenter.asu.edu/sites/default/files/ sites/default/files/problems/PDFs/abandoned buildings and lots.pdf (Consultado el 7 de marzo de 2020).

Tambi, Sergei (2016). The Contemporary Development of the Concept of the Twin Cities: The Case of Cross-Border Cooperation between Narva and Ivangorod. Tesis para obtener el grado de Maestría en Ciencias Políticas. Johan Skytte Institute of Political Studies, Faculty of Social Sciences, University of Tartu, Disponible en: https://core.ac.uk/download/ pdf/79117491.pdf (Consultado el 18 de agosto de 2020).

Trancik, Roger (1986). Finding Lost Space, Theories of Urban Design. New York, United States of America: Van Nostrand Reinhold Company. 